\title{
Confidence Building on Euro Convergence: Theory and Evidence from Currency Options
}

\author{
Joost Driessen \\ University of Amsterdam \\ Enrico Perotti \\ University of Amsterdam and CEPR
}

October, 2003

\begin{abstract}
We are indebted to Kevin Chang, Magnus Dahlquist, Stephen Taylor, Robert Tompkins, and seminar participants at the World Bank, IMF, European Central Bank, University of Amsterdam, the 2003 ESSFM Gerzensee meeting, the 2003 EFA meeting in Glasgow for precious comments. We thank Kevin Chang and Credit Suisse First Boston in London for the option data. Roger Laeven provided able research assistance.

Correspondence address of both authors: Finance Group, Faculty of Economics and Econometrics, University of Amsterdam. Roetersstraat 11, 1018 WB, Amsterdam, the Netherlands. E-mail: j.j.a.g.driessen@uva.nl and e.c.perotti@uva.nl.
\end{abstract}




\title{
Confidence Building on Euro Convergence: Theory and Evidence from Currency Options
}

\begin{abstract}
Using a new dataset of currency option prices, we study the evolution of investor confidence in 1992-1998 over the chance of individual currencies to converge to the Euro. Convergence risk, which may reflect uncertainty over policy commitment as well as exogenous fundamentals, induces a level of implied volatility in excess of actual volatility (volatility wedge). We show formally that confidence grows over time as convergence policy is maintained, and the risk of a reversal is progressively resolved. Empirically, we indeed find a positive volatility wedge which declines over time, only for those currencies involved in convergence. The wedge and other convergence risk measures are correlated with both observable fundamentals and proxies for policy commitment uncertainty. We also find that the wedge responds to policy shocks in an asymmetric fashion, suggesting that policy risk is resolved at different rates after negative and positive shocks, as the confidence building model suggests. Finally, we estimate a regime-switching model of convergence uncertainty, using data on interest rates, currency rates, and currency option prices. The results confirm the time-varying and asymmetric nature of convergence risk, and indicate that investors demand a risk premium for convergence risk.
\end{abstract}

JEL classification: C22; F21; F34; G13; G38.

Keywords: Convergence risk; Confidence building; Currency options; Regime switching models. 


\section{Introduction}

Financial prices reflect uncertainty and reveal information about its resolution. Many causes of uncertainty are exogenous and are naturally resolved over time. Some other source of uncertainty is instead of a strategic nature, as the timing of its resolution is a strategic variable by some agents with incentives to hide their information. For instance, managers of poorly performing firms may hide bad news or delay their disclosure, when this would reduce financing costs or delays default. Similarly, governments may hide unfavorable news, when they receive some short-term benefits from investor confidence on their policy. Because of this incentive to hide bad news, or to time strategically their release, confidence on the true performance of a corporation or future government policy can only be established gradually. The recent series of corporate accounting scandals has revealed the degree of misrepresentation possible even in sophisticated financial markets such as the US, and has certainly hurt confidence on the reliability of reported profitability. Similarly, there have many cases of misrepresentation by governments on their intentions or ability to implement an announced policy. A classic example was the attempt of the Mexican treasury to hide a sharp decline in foreign reserve ahead of the peso crisis of 1994, which in turn prompted the IMF to establish a program for timely releases of such official statistics for many countries.

We argue that in such cases financial prices must reflect, in addition to the uncertainty surrounding exogenous factors, also the evolution of this strategic concealment of information. We consider in this paper the context of an uncertain government commitment to an exchange rate target, where the possibility of strategic behavior implies a gradual updating of investor's beliefs, a process we term "confidence building". The first contributions to this literature were the models of uncertain disinflationary policy in Barro (1986) and Rogoff (1986). ${ }^{1}$

The main goal of this paper is to present a methodology to empirically assess the relevance of confidence building for financial prices, and offer as an empirical example

\footnotetext{
${ }^{1}$ Other examples are uncertain protection of property rights of foreign investors in Cherian and Perotti (2001), and uncertain commitment to privatization policy as in Perotti and van Oijen (2001) and Laeven and Perotti (2002).
} 
the process of convergence of several European currencies to the Euro in the period 1992-1998. At the time, the political determination to sustain the process of convergence remained uncertain in several countries until the final conversion, making this a very suitable test for our confidence building hypothesis. Particularly countries with a tradition of higher inflation and high budget spending, such as Spain, Belgium, and Italy, were at times considered unlikely to complete the convergence process, and yet had an incentive to claim a commitment to convert in order to reduce interest rates and inflationary expectations. $^{2}$ As it is likely that other countries will join the Euro in the future, understanding this specific convergence process is also important.

In short, we provide empirical evidence for a gradual updating of beliefs on the commitment of the policymakers in the different countries to fully meet the Maastricht Treaty criteria for inclusion, and assess the implications of this confidence building process for currency option prices and currency volatility. We use an extraordinary dataset of daily cross-rate option prices between 1992 and 1998 for six European countries, four of which joined the Euro.

The first part of the paper introduces a reference model of confidence building. In the model, countries with high fiscal deficits claim a commitment to conversion even if the authorities are not able or willing to follow the process through. The policy can be reversed at any point in time, but in the short term it allows the government to capture the benefit of lower interest rates. Once the cost of policy commitment exceeds the benefits, however, the country will abandon its convergence policy. Policy uncertainty thus becomes progressively resolved as no reversal is observed.

We argue that this policy risk causes option prices to reflect a high implied volatility, in excess of actual volatility. As confidence grows over time (in the absence of policy reversals), implied volatility falls. In addition, there is a positive, but decreasing difference between implied and actual volatility throughout the policy implementation period. This volatility wedge reflects the potential increase in exchange rate volatility which would take place, were the country to drop out of the convergence process.

\footnotetext{
${ }^{2}$ All countries which requested to be included ultimately joined in 1998 (except the drachma which joined a few years later); yet for most of the 1990s there remained well founded uncertainty among observers on the ability of governments in some countries to take the hard actions required.
} 
In the empirical analysis we focus on three measures of convergence risk, the volatility wedge, the implied currency volatility, and a country's interest rate spread relative to the German interest rate. The interest rate spread has been used previously to assess the likelihood of Euro convergence (section 2 discusses this literature). First of all, we show that a positive average wedge exists for the converging currencies, while the wedge is small for countries that did not participate in the convergence process. Moreover, for the converging currencies there is a clear decreasing trend in the wedge over time, which approaches zero smoothly in 1998. For the non-participating countries, the wedge shows no systematic behavior. For the other two risk measures we also observe a decreasing pattern over time.

This decrease in the convergence risk measures may be (partially) caused by changes in observable variables, which influence the objective probability of convergence. We therefore use a regression analysis to disentangle such exogenous learning from confidence building. In a first step, we analyze a fixed-effects panel data model and regress each risk measure across countries on the budget deficit and the inflation rate. These two variables were used in the Maastricht Treaty to set convergence criteria, and are therefore the critical variables to capture learning about observable indicators of the likelihood of convergence. Indeed, the results show that the several risk measures are positively related to the level of the budget deficit and the inflation rate. In a second step, we study the residuals of the first-step regression to see if this residual risk is correlated with policy risk variables. We also test whether residual uncertainty contains a downward trend, in line with the confidence building hypothesis. The empirical results indeed show a downward trend in the residuals over time. In addition, the residuals are significantly related to the ICRG political risk measure, which proxies for the stability in economic policy.

Next, we study a more subtle implication of the confidence building model. Over time, investors will observe some economic and political shocks, which may affect the cost of convergence policy. In particular, large negative shocks represent a challenge to the policy in place. As a result, if the policy is maintained under such unfavorable circumstances, investors would gain confidence faster than in the absence of the shock. In contrast, a more moderate reaction is expected after positive shocks. Thus, the speed of 
the decline in the risk measure (a measure of the rate of confidence building over time) should be affected asymmetrically by policy news. This implication of the confidence building model distinguishes it from a purely exogenous learning model. Empirically, we indeed find evidence that all risk measures (the volatility wedge, the interest rate spread and the implied volatility) react asymmetrically to past changes. Increases in these variables are typically reversed quickly, while decreases are not. These asymmetric patterns are clearly different from a standard GARCH model, which predicts symmetric and persistent effects of shocks.

In the final part of the paper, we incorporate the credibility model in a regimeswitching model formulation. In order to capture the time-varying and asymmetric nature of convergence risk, we allow the regime-switching probabilities to depend on the interest rate spread. We also allow for a risk premium on convergence risk (the risk of regime switches). In order to estimate our model efficiently, we develop a new estimation strategy to use both the information in currency movements and currency option prices. To the best of our knowledge, this paper is the first to estimate a risk premium on regime switches. The model estimates confirm the empirical results presented in the first part of the paper. Furthermore, we find clear evidence that investors require a risk premium for convergence risk. Finally, the model also yields a time series of convergence probabilities, which we compare with the EMU-probabilities based on interest rates.

The rest of this paper is organized as follows. In section 2 we discuss related research. Section 3 presents the theoretical model. In section 4 we empirically test the implications of the theoretical confidence building model. Section 5 discusses the regimeswitching model for convergence risk, and presents estimation results for this model. Section 6 concludes.

\section{Related Empirical Research}

The empirical literature on convergence to the Euro has used mostly data on interest rate spreads. In particular, several so-called EMU calculators have been developed (see, for example, Lund (1999), Bates (1999), and Favero et al. (2000)). These calculators used cross-country bond spreads to assess the probability that a country would join the EMU. 
A disadvantage of using bond spreads is that these spreads do not have to disappear completely in case of convergence. In fact, since the fixing of the currency rates January 1, 1999, Italian government bonds still trade at a significant liquidity spread to, for example, German government bonds. Also, as shown by Lund (1999), for some nonconverging countries, especially Sweden, the interest rate spread pattern over the 19951998 period very much resembled the spread behavior of converging countries. Finally, Lund (1999) shows that it is hard to analyze the convergence uncertainty for countries for which had small interest rate spreads already at the beginning of the convergence process, such as Belgium, France, and the Netherlands.

The approach proposed here is to exploit the much richer information available from options. Related to this is the work by Campa et al (1998ab) and Maltz (1996), who have used these data to assess the credibility of currency target zones. Interestingly, the early literature on the Euro, which analyzed the devaluation crisis of 1992, found evidence that investors had envisioned the potential collapse of the pound and lira by analyzing option prices (Campa and Chang (1996)). In other settings, extracting information on higher distributional moments from prices has been studied in seminal contributions by Jackwerth and Rubinstein (1996) and Ait-Sahalia and Lo (1998), who extract the risk-neutral state-price density from traded option prices.

Other related literature includes the papers by Dumas, Jennergren, and Naslund (1995a, 1995b), which price options on currencies with jumps. Their models take the jumps as exogenous and cannot incorporate the learning behavior of investors in the presence of convergence risk. Bottazzi and Hueffman (2000) develop a model for pricing currency options when there is uncertainty about convergence to a fixed peg, but jumps are exogenous and there is no confidence building by investors. Adao and Barros (2000) use interest rate option prices to assess the likelihood of Euro convergence. Since interest rate options do not directly contain information on this likelihood, they have to assume a value for the correlation between interest rates of different countries. 


\section{Theoretical Model}

We outline here a simple credibility model based on Barro (1986) and Rogoff (1987), who analyze the evolution of confidence when investors are uncertain about the commitment of policymakers and there is no credible signal available. In that case, credibility can be established only gradually by maintaining the announced policy over time, since uncommitted policymakers will gradually reveal their preferred strategy by abandoning the convergence policy. The optimal reversal strategy thus endogenizes the hazard rate of a policy change, and determines the rate of confidence building by investors.

Consider the following simple model of policy choice over an interval $t=1, . . \mathrm{T}$. Investors are uncertain about policy commitment because the government faces an unknown political cost $\mathrm{C}$ to maintain the convergence policy. Assume that at each date $\mathrm{t}$ they have beliefs about the distribution of political cost $\mathrm{C}_{\mathrm{t}}$ for the government. ${ }^{3}$ This cost may be time-dependent and subject to shocks. Once this cost exceeds the benefits of convergence, the government will abandon its convergence policy.

The benefit of convergence is high credibility of monetary and fiscal policy, so that the interest rate on the public debt $\mathrm{D}$ will be low and equal to $\mathrm{r}$. Assume that the public debt is short term, so its rate is adjusted in each period to reflect the perceived risk of a policy change. Assume that a government which drops out of convergence policy faces a higher interest rate cost of servicing its debt $\mathrm{D}$ equal to $\mathrm{R}$, where $\mathrm{r}<\mathrm{R}$. Maintaining a converging policy until time $t$ lead to an interest rate $r_{t}$ which reflects the expected return

$$
r_{t}=r\left(\theta_{t}\right)=\theta_{t} R+\left(1-\theta_{t}\right) r
$$

where $\theta_{\mathrm{t}}$ reflects investors' perceived probability that the government will abandon convergence policy at time t. Once the government changes its policy, there are no longer

\footnotetext{
${ }^{3}$ A government which by ideology is strongly favorable to convergence policy may even have a negative cost $\mathrm{C}$. In general there may be some correlation between the cost $\mathrm{C}$ and the level of public debt $\mathrm{D}$.
} 
any doubts on its type, so that $\theta_{\mathrm{t}}=1$ for all $\mathrm{t}$ thereafter and the cost of debt remains at $\mathrm{R}$. Thus in any given period, the government will have a utility flow equal to

$$
\mathrm{U}_{\mathrm{t}}^{\mathrm{C}}=-\mathrm{C}_{\mathrm{t}}-\mathrm{r}\left(\theta_{\mathrm{t}}\right) \mathrm{D}_{\mathrm{t}}
$$

if it maintains the convergence policy, while if it abandons it will have

$$
\mathrm{U}^{\mathrm{A}}{ }_{\mathrm{t}}=-\mathrm{RD}_{\mathrm{t}}
$$

We assume no discounting. The government minimizes at time 0 a loss function by choosing an optimal switching timing $\mathrm{t}^{*}$

$$
\operatorname{Max}_{t^{*}} \Sigma_{t}{ }^{\mathrm{T}} \mathrm{U}_{\mathrm{t}}=-\Sigma_{1}{ }^{\mathrm{t}^{*}} \mathrm{C}_{\mathrm{t}}-\left(\mathrm{T}-\mathrm{t}^{*}\right) \mathrm{RD}-\Sigma_{1}{ }^{\mathrm{t}^{*}} \mathrm{r}\left(\theta_{\mathrm{t}}\right) \mathrm{D}
$$

Initially, each government chooses a pure strategy in $\mathrm{t}^{*}$, with a committed government choosing an infinite $t^{*}$. More generally, for each date $t$ there is a critical political cost threshold $\mathrm{C}^{*}{ }_{\mathrm{t}}>0$ such that countries with political costs $\mathrm{C}_{\mathrm{t}}<\mathrm{C}^{*}{ }_{\mathrm{t}}$ will maintain the convergence policy while the others will reverse it immediately. Intuitively, countries with high $\mathrm{C}$ will reverse earlier, since the reduction in interest rates will at some point be too modest to compensate for the ongoing cost of the converging policy. ${ }^{4}$ This formulation follows closely the model in Rogoff (1987).

Any realistic representation of actual currency prices requires some intertemporal variation in risk perception besides a gradually vanishing risk of a reversal. We thus introduce observable interim shocks to the political cost of convergence, which will affect the policy trade-off and thus perceived risk. Specifically, we assume that the cost $\mathrm{C}_{\mathrm{t}}$ varies over time, reflecting both a predictable component and some mediumfrequency, intermediate-size shocks. In order to generate some learning at each date, we assume that per-period political costs increase as convergence policy progresses, ${ }^{5}$ a

\footnotetext{
${ }^{4}$ For a more general model of endogenous timing of policy change, see Cherian and Perotti (2001). For a related model of progressive separation with discrete types, see Laeven and Perotti (2002).

${ }^{5}$ If these costs were to decline in each period, there would be no interim reversal: an uncommitted government would either switch immediately or wait until the very last period.
} 
realistic assumption if early steps in convergence policy are relatively easy relative to more structural medium term adjustment to be taken over time. Specifically, let

$$
\mathrm{C}_{\mathrm{t}}=\mathrm{C}_{\mathrm{t}-1}(1+\delta)^{\mathrm{t}}+\varepsilon_{\mathrm{t}}
$$

where $\varepsilon$ is an independently distributed random variable with zero expectation. ${ }^{6}$

We assume that investors know the distribution of government types $C_{t}$ at each date $t$, and observe any interim shocks $\varepsilon_{\mathrm{t}}$. We simplify the model by assuming that the government does not attempt to incorporate the presence of future shocks in its optimal timing choice, and chooses to abandon the convergence policy at time $t$ if the flow of political costs exceeds the per period financial saving, $C_{t}>\left[\left(R-r\left(\theta_{t}\right)\right) D_{t}\right]$. Figure 1 illustrates the optimal reversal timing for a hypothetical government with an initial political cost of $\mathrm{C}_{\mathrm{o}}$.

The implied per-period hazard rate $\theta_{\mathrm{t}}$ reflects the fraction of governments whose optimal timing of reversal is t. The computation of the distribution of reversal over time requires solving backwards. Define $\mathrm{T}^{*}$ to be the date by which the government is no longer expected to abandon its convergence policy. This may occur before $\mathrm{T}$, the formal date of final conversion (we assume that after $\mathrm{T}$ any reversal is too costly). For this belief to be rational, it must be that a government which has not reverted so far cannot possibly gain from switching at $\mathrm{T}^{*}$; thus its political $\operatorname{cost} \mathrm{C}_{\mathrm{T}}$ must be less than a critical $\mathrm{C}^{*}{ }_{\mathrm{T}}$ such that $\mathrm{C}^{*} \mathrm{~T}=(\mathrm{R}-\mathrm{r}) \mathrm{D}_{\mathrm{T}}$, which is the maximum gain from fooling investors into believing that $\theta_{\mathrm{T}}$ is zero. We can now define the critical threshold at T-1 as

$$
\mathrm{C}^{*}{ }_{\mathrm{T}-1}=\left[\mathrm{R}-\mathrm{r}\left(\theta_{\mathrm{T}-1}\right)\right] \mathrm{D}_{\mathrm{T}-1}
$$

$\theta_{\mathrm{T}-1}$ is strictly related to $\mathrm{C}^{*} \mathrm{~T}-1(1+\delta)$, since it represents the chance that the government will have a political cost between $\mathrm{C}^{*} \mathrm{~T}-1$ and $\mathrm{C}^{*} \mathrm{~T}$, based on the distribution of government types conditional on no reversal until T-1, plus the fact that no type with a cost above $\mathrm{C}^{*} \mathrm{~T}$ at time $\mathrm{T}$ will find it optimal to maintain convergence 


$$
\theta_{\mathrm{T}-1}=\operatorname{Prob}_{\mathrm{T}-1}\left[\mathrm{C}^{*}{ }_{\mathrm{T}-1}<\mathrm{C}_{\mathrm{T}-1}<\mathrm{C}_{\mathrm{T}} /(1+\delta) \mid\right. \text { no reversal until T-1] }
$$

Solving this equation recursively for all $t$ generates the equilibrium time series of hazard rates $\theta_{\mathrm{t}}$.

The implication of this simple model is that in each period without a policy change, investors will update their beliefs on the credibility of an individual country's commitment to convergence (since some high political cost types would have reversed policy). We call this evolution of credibility "confidence building". Investor confidence will evolve in each date $t$ according to Bayes' Law: $p_{t}=p_{t-1} /\left(1-\theta_{t}\right)$.

Note that $\theta_{\mathrm{t}}$ determines the difference between expected (implied) and actual (ex post) volatility on the currency at date $t$, as a policy reversal would generate an increase in currency volatility. In Figures 2a-b we show the result of simulations on the model, ignoring any interim shocks to the political cost of convergence. ${ }^{7}$ The model implies unambiguously a gradual learning over time, and a declining hazard rate. As a result, both total and per period perceived risk will fall over time.

We next consider the effect of large interim shocks $\varepsilon$ on the time path of perceived convergence risk. Intuitively, periods in which convergence policy is maintained even though its costs have risen (e.g. as a result of a major price shock, a massive labor strike, or an unanticipated recession) are particularly informative about the degree of government commitment. As a result, investors will increase their expectation about the chance of a reversal in the following periods. In particular, a large negative news shock will lead to an increase in the "rate of learning". If no reversal is observed, this implies that the government is "more committed" than previously expected (i.e. has a lower political cost than previously believed), leading to a faster confidence build-up.

In Figure 2a we illustrate the effect of a large negative news shock (an increase in the political cost). The hazard rate jumps upon the shock, reflecting both an overall greater chance of reversal and a larger hazard rate for the next period. The simulation also shows that the hazard rate drops rapidly, reflecting the faster confidence building derived from the greater likelihood of an immediate reversal. Figure $2 b$ shows the effect of $a$

\footnotetext{
${ }^{6}$ In practice, such shocks are likely to be correlated across countries.
} 
large positive news shock, where the hazard rate decreases, but the size of the decrease is much smaller than the increase in the hazard rate after negative news.

\section{Analysis of Convergence Risk Measures}

In the empirical analysis we condition upon participation of Germany to the Euro (as in Lund (1999)). For each country, we then construct three measures of convergence risk for our empirical tests. The first measure is the spread between a country's interest rate and the German interest rate. Several others have used this interest rate spread (IRS) measure in the context of Euro convergence (see section 2). As indicated in section 2, there are several reasons why currency option prices contain additional information on Euro convergence. Our second and third risk measures therefore exploit the information in currency option prices. The second measure is the implied volatility (IV) of a currency option, and the third measure is the volatility wedge (VW), which is defined as the difference between the implied currency volatility and the realized volatility of the currency over the life of the option.

The implications of the theoretical model in section 2 can then be translated to the following hypotheses for these risk measures. First of all, the volatility wedge should be positive for converging countries, due to the uncertainty about convergence and, in addition, a risk premium on this risk. Second, residual uncertainty about convergence is decreasing over time, implying a decreasing trend in the time series of the IRS, IV, and VW. Third, after controlling for observed changes in economic conditions affecting convergence, all risk measures should be related to proxies for policy risk. Finally, the theoretical model implies that the rate of confidence building increases after unfavorable economic or policy shocks. In this section we analyze these four hypotheses.

\footnotetext{
${ }^{7}$ The simulations assume a uniform distribution of types, $r=3 \%, \mathrm{R}=11 \%, \mathrm{D}=50$ or 75 , and an average political cost $\mathrm{C}_{\mathrm{o}}=10$ rising marginally (at a rate of $0.1 \%$ ) over time till $\mathrm{T}$.
} 


\subsection{Data}

We use a new and unique dataset, which consists of direct quotes on cross rate currency options gathered by the forex desk of Credit Suisse First Boston in London, an international investment bank with a significant role in European currency trading. We also have daily data on the related cross-rate currency and forward prices. Importantly, we have every day a new set of options, whose exercise price is set at the current forward rate.

All options are on currency rates relative to the Deutschemark. Data are available for six countries. Four of these countries, Belgium, France, Italy, and Spain, eventually joined the Euro, while the other countries, Sweden and the UK, did not participate in the convergence process. The data consist of quotes for option-implied volatilities for five different maturities: 1, 2, 3, and 6 months, and 1 year. Data start in March 1991 for the UK, June 1994 for Belgium and in 1992 for all other countries.

For our analysis we also use data on interest rates and economic fundamentals. We do not use government bonds to construct interest rates, since it is well known that there are liquidity differences across maturities and across countries. Instead, we follow Lund (1999) and use data on 10-year swap rates for all relevant countries, collected from Datastream. For all six countries we construct the interest rate spread by subtracting the German swap rate from the country's swap rate.

Finally, for each country, we collect data on monthly inflation rates, the yearly budget deficit, and a monthly political risk indicator. This political risk indicator is the political risk index from the International Country Risk Guide (ICRG) (see Erb, Harvey, and Viskanta (1996) for details). This indicator is between 0 and 100, where 100 corresponds to the lowest possible political risk. In our analysis we use the negative of this indicator, so that higher values for the political risk variable correspond to higher political risk. 


\subsection{Volatility wedge}

We define the volatility wedge as the difference between implied volatility ${ }^{8}$ (IV) of an option and the realized currency volatility over the remaining maturity of the option. We choose to use the 2-month option to construct the volatility wedge. This choice reflects a trade off between liquidity of the option and the accuracy of the estimate of the realized volatility: short-maturity options are typically more liquid than options with longer maturities, but for such options fewer observations can be used to calculate the realized volatility. In case of the 2-month option, slightly more than 40 trading days can be used to calculate the realized currency volatility, which is defined as the annualized standard deviation of daily changes in the log-currency rate. Both the volatility wedge and the implied volatility are measured in volatility points. This procedure of calculating realized volatility is also used by, for example, Canina and Figlewski (1993), who compare implied volatilities of equity index options with realized volatility on the underlying equity index.

For each country, these calculations provide a wedge measure at all days in the dataset. Figures 3-8 graph the behavior of these volatility wedges, along with the implied volatility, over the 1992-1998 period. Table 1 provides some basic summary statistics on the volatility wedge.

The results on the volatility wedge and implied volatility give first support to the presence of confidence building. On average, there is a considerable positive volatility wedge for the converging countries, ranging from 0.44 volatility points for France to 1.69 volatility points for Spain. Furthermore, the quartiles of the volatility wedge distribution show that the wedge is positive at most days. For the countries that did not participate in the convergence process, the average wedge is much closer to zero, 0.19 volatility points on average for Sweden and 0.25 for the UK, and negative wedges occur more frequently. For these countries there appears to be no convergence risk, likely because no convergence is expected.

\footnotetext{
${ }^{8}$ Note that the correct option pricing model is not Black and Scholes, since the price process is not the standard geometric Brownian motion. The Black and Scholes' implied volatility measure is utilized only to compute the standard implied volatility metrics.
} 
In addition to the average size of the wedge, Figures 3-6 show that for the converging countries there is a decreasing trend in the volatility wedge and implied volatility over time. Besides the time trend, the graphs also illustrate the high uncertainty during the crises in September 1992, August 1993, and March 1995. These crises result in higher implied volatilities and large changes in the volatility wedge. From mid-1995 onwards, there are no extreme movements in implied volatilities and the volatility wedge, and the gradual reduction of convergence uncertainty is especially clear. Eventually, the volatility wedges of all converging countries approach zero in May 1998, when it became clear which countries would join Euro and which not. In contrast, the time series behavior of the implied volatility and volatility wedge for Sweden and UK is quite irregular, and no particular pattern comes forward (Figures 7-8).

In table 2 we provide summary statistics on the implied volatilities, and, for comparison, we include statistics on the interest rate spread for all countries. The table shows that the non-converging countries have higher average and median implied volatilities than the converging countries, in line with our findings for the volatility wedge. Interestingly, on the basis of interest rate spreads a clear differentiation of converging and non-converging countries is not possible. On average, Sweden and the UK both have smaller interest rate spreads than Italy and Spain. Moreover, as noted by Lund (1999), the time series pattern of the Swedish interest rate spread very much resembles the pattern that is observed for the converging countries. This shows that it is indeed useful to consider the information in currency rates and currency options for Euro convergence risk, in addition to the interest rate spread.

\subsection{Disentangling confidence building and exogenous learning}

Next, we focus on the determinants of the convergence risk measures. In particular, we first try to correct the risk measures for so-called exogenous learning variables. We then analyze whether the residual uncertainty is correlated with variables that are related to the confidence building process. We follow a two-step procedure.

In the first step we regress each risk measure on the budget deficit and inflation, using a fixed-effects panel data model for the four converging countries. Since the 
Maastricht treaty explicitly indicated upper bounds for the budget deficit and the inflation rate, these variables account for what we call exogenous learning. The measures for convergence risk should directly be related to these two variables, because changes in inflation rates and budget deficit clearly influence the likelihood of Euro convergence, irrespective of whether governments behave strategically or not when determining their convergence policy.

We collect these data on a monthly frequency from Datastream, except for the budget deficit, which has a yearly frequency. ${ }^{9}$. In formulas, we estimate the following regression equation for the IV

$$
I V_{i, t}=\alpha_{i}+\beta_{1} \text { Inflation }_{i, t}+\beta_{2} \text { BudgetDeficit }_{i, t}+\varepsilon_{i, t} \quad i=1, \ldots, 4, t=1, \ldots ., T
$$

with the usual assumptions on the error term. ${ }^{10}$ Similar equations are estimated for the volatility wedge and the interest rate spread. Equation (8) shows that we allow the constant term to vary across countries, while the slope parameters are assumed to be constant across countries. We use the fixed-effects (or within) least-squares estimator to estimate the parameters in equation (8).

In a second estimation step, we regress the residuals of the regression in (8) on two proxies for confidence building and the associated strategic behavior of governments. The regression residuals, which are corrected for observed changes in the likelihood of convergence, represent the residual uncertainty about the commitment to convergence policy. The first proxy is a linear time trend. According to the confidence building model discussed in section 3, residual uncertainty about policy commitment decreases over time, implying a negative time trend in residual uncertainty. The second proxy is the ICRG political risk measure discussed above. This measure should capture variation in the political stability of a country, which we expect to be related to investor uncertainty about policy commitment. Again, we pool the time series of all four converging countries and estimate a fixed-effects panel data model.

\footnotetext{
${ }^{9}$ The wedge is observed at the date when the realized volatility is observed. By construction, this is two months after the observation of the implied volatility of the option with a 2-month maturity.

${ }^{10}$ Since budget deficit is only observed on a yearly basis, we assume this variable to be piecewise constant year by year.
} 
The regression results are given in table 3. We first discuss the first-step regression results. Both the inflation rate and budget deficit have a statistically significant relationship with the three risk measures at the $10 \%$ level. The economic size of the coefficients is also significant. For example, an increase in monthly inflation of $0.1 \%$ (e.g., from $0.2 \%$ to $0.3 \%$ ) gives an expected increase in the IV of 0.1 volatility points. In all cases, there is a positive relationship between the risk measures and the inflation and budget deficit, in line with economic intuition. The results for the IV and IRS regressions are statistically much more precise than the results for the wedge, as a higher $\mathrm{R}^{2}$ is obtained ( $42.3 \%$ for the IV and $49.4 \%$ for the IRS). This confirms the impression that our estimates of the wedge are noisy, which is due to the fact that the realized volatility is estimated using 2 months of currency data.

Next we regress the residuals of the first-step regression on the time trend and the ICRG political risk measure. For all risk measures, both variables are significant at the $10 \%$ level and have the expected signs. The time trend implies an annual decrease of about 0.24 volatility points for the IV and the wedge, and about $0.17 \%$ for the interest rate spread. Thus, even after controlling for observed increases in the likelihood of Euro convergence caused by decreasing inflation rates and budget deficits, the convergence risk measures exhibit a downward trend over time. For the political risk measure we find that an (often observed) increase of 1 point in the political risk indicator (e.g., from -80 to -79) implies an expected IV decrease of 0.15 volatility points. The $\mathrm{R}^{2}$ of the secondstep regression ranges from $9.4 \%$ for the wedge to $21.5 \%$ for the interest rate spread. Although, compared to the exogenous learning variables (inflation rate and budget deficit) the explained variation is somewhat smaller, these results show that the confidence building proxies do explain part of the residual variation in the risk measures.

\subsection{Time-variation in the rate of confidence building}

The results above show that there is gradual improvement in the wedge, implied volatility and interest rate spread over time. In line with the analysis of intermediate shocks for the theoretical model, we now analyze whether there are moments when a country is 'stress- 
tested', leading to faster confidence building of investors than on average. ${ }^{11}$ In particular, we are interested whether there is an asymmetric reaction of the risk measures to positive versus negative policy shocks. Note that any evidence of asymmetry would imply a timeseries behavior that is different from a standard GARCH model, in which shocks have a persistent and symmetric effect.

To analyze this asymmetry for the IV, we regress weekly changes in the IV, $\Delta I V_{i, t+1}$, on two variables, $\left(\Delta I V_{i, t}\right)^{+}=\max \left(\Delta I V_{i, t}, 0\right)$, and $\left(\Delta I V_{i, t}\right)^{-}=\min \left(\Delta I V_{i, t}, 0\right)$, thus allowing for an asymmetric reaction to positive and negative changes. We perform the same regression for the interest rate spread. We focus on a weekly frequency, but similar results are obtained for monthly data.

The results in table 4 show that both risk measures react in an asymmetric fashion to past shocks. For all countries, increases in IV or IRS are typically followed by subsequent decreases. This effect is significant on the $10 \%$-level for 5 out of 8 cases. For a lagged decrease in the IV or IRS, no economically or statistically important reaction is observed. These results are in line with our model of strategic policy behavior: after a temporary, large increase in convergence risk, faster confidence building about the country's commitment is observed. Note that our data relate to countries that all converged eventually. Clearly, we would expect different time series behavior for a country that did not converge.

Next, we analyze whether the time series of the volatility wedge also reflects the asymmetry discussed above. Because the volatility wedge exhibits positive autocorrelation by construction, we use a different methodology. To distinguish infrequent but important policy shocks from regular but small daily market shocks, we perform the following analysis. Per country, we select from all weekly interest rate spread shocks the shocks in the lower 2.5\%-percentile and the upper $97.5 \%$-percentile. We then look at the behavior of the wedge when such large IRS shocks take place. We investigate both the contemporaneous change in the wedge, and the subsequent changes

\footnotetext{
${ }^{11}$ A concrete example can illustrate this point. A major strike by public workers occurred in France in 1995, in response to budget cuts required by the Maastricht treaty. It led to a sharp jump in the interest rate spread, as investors feared that it may lead to policy changes which would undermine French budget discipline. As such fears regressed, the increase in interest rate spread was rapidly reabsorbed. Clearly, the strike represented a threat to the convergence process, but also a test of commitment. Sustaining policy in such circumstances is thus particularly informative, and leads to a faster rate of learning.
} 
in the wedge. We correct for the average trend in the wedge, by calculating all changes in the wedge in deviation from the average change.

Table 5 shows the following results. At the time of a large positive shock to the interest rate spread, the wedge increases by a large amount. This reflects the sudden increase in uncertainty on Euro participation. However, the tables show that, for the converging countries, this uncertainty is resolved over time: after 4 weeks the level of the wedge is in all cases (except France) lower than the level of the wedge directly after the initial interest rate spread shock. Moreover, for Spain the wedge is lower after 4 weeks than the wedge before the large IRS shock. Again, this indicates that in times of high uncertainty, investors learn faster about the true nature of the country than in normal market circumstances.

At the time of a large decrease in the interest rate spread, an abnormal decrease in the wedge is observed in the week of the shock, which is however smaller in absolute size than the increase in the wedge after a positive IRS shock. This shows that the wedge reacts asymmetrically to policy news. In the weeks following the large negative IRS shock, the wedge decreases somewhat more. A possible explanation of this result is the following. The initial decrease in the IRS is an indication of improvement in the likelihood of Euro participation. However, the good news that underlies this improvement is typically 'soft' news, which is therefore not reflected completely in option prices in the first week. Only over time, the true value of this soft news becomes clear to investors.

\section{Modelling Convergence Risk as a Regime-Switching Model}

\subsection{Model description}

In this section we propose a reduced-form currency option pricing model that incorporates the credibility building process. This will allow us to quantify the risk premium on convergence risk demanded by investors. In addition, the model proposed below gives an option-implied estimate of the likelihood of Euro convergence, which can 
be compared to EMU-calculators based on interest rate spreads (see Favero et al. (2000) and Lund (1999)).

Our model builds on the literature of regime-switching models, introduced by Hamilton (1989) and applied to financial markets by, amongst others, Dahlquist and Gray (2000), Ang and Bekaert (2001) and David and Veronesi (2002). In our model, a country's currency rate (relative to Deutschemark) can be in two regimes, a convergence and a no-convergence regime. Investors do not observe in which regime the currency is, and regime switches are possible before the final convergence date. One may think of these two regimes as a low political cost regime and a high political cost regime, in line with the model in section 2 where investors are uncertain about the true political cost of the country.

The first regime is the convergence regime, in which the currency rate $S_{t}$ satisfies

$$
\frac{S_{t}-S_{t-1}}{S_{t-1}}=\mu_{c}+\sigma_{c} \varepsilon_{t}
$$

In equation (9) $\varepsilon_{t}$ is a normally distributed innovation, $\mu_{c}$ is the drift rate, and $\sigma_{c}$ is the currency volatility. We assume that the volatility in the convergence regime is generated by noise trading, so that this volatility is expected to be small. We use weekly changes for the currency rate in equation (9).

The second regime is the no-convergence regime

$$
\frac{S_{t}-S_{t-1}}{S_{t-1}}=\mu_{n c}+\sigma_{n c} \varepsilon_{t}
$$

We expect the currency volatility $\sigma_{n c}$ in this regime to be higher than in the convergence regime. Also, one may expect the drift rate to be negative in the no-convergence regime, reflecting a further devaluation of the currency. The model is completed by assuming a first-order Markov process for the current regime in a country. Regime changes from time $t$ to time $t+1$ are governed by the regime-switching probability matrix $P_{t}$ 


$$
P_{t}=\left[\begin{array}{cc}
p_{c, c}\left(x_{t}\right) & 1-p_{c, c}\left(x_{t}\right) \\
1-p_{n c, n c}\left(x_{t}\right) & p_{n c, n c}\left(x_{t}\right)
\end{array}\right]
$$

Here $p_{c, c}\left(x_{t}\right)$ is the probability of staying in the convergence regime from time $t$ to $t+1$. To incorporate time-varying convergence risk, we allow the switching probabilities to depend on conditioning variables $x_{t}$, using the following specification

$$
p_{c, c}\left(x_{t}\right)=\Phi\left(\alpha_{c}+\beta_{c} I R S_{t}+\gamma_{1, c}\left(\Delta I R S_{t}\right)^{+}+\gamma_{2, c}\left(\Delta I R S_{t}\right)^{-}\right)
$$

and

$$
p_{n c, n c}\left(x_{t}\right)=\Phi\left(\alpha_{n c}+\beta_{n c} I R S_{t}+\gamma_{1, n c}\left(\Delta I R S_{t}\right)^{+}+\gamma_{2, n c}\left(\Delta I R S_{t}\right)^{-}\right)
$$

Gray (1996), Dahlquist and Gray (2000), and Ang and Bekaert (2001) use similar specifications to incorporate conditioning information. In our case, we use as conditional variables the level of the interest rate spread in week $t, I R S_{t}=r_{t}-r_{t}^{D M}$, and both the maximum and minimum of zero and the change in this spread from week $t-1$ to $t$, $\left(\Delta I R S_{t}\right)^{+}$and $\left(\Delta I R S_{t}\right)^{-}$. Dahlquist and Gray (2000) also use the interest rate spread as a conditioning variable when studying the impact of currency target zones on interest rate behavior. As shown in the previous section, the level of the interest rate spread is positively related to the size of convergence risk. We thus expect the slope coefficient $\beta_{c}$ for the level of interest rate spread to be negative for the convergence probability. If the interest rate spread (and thus convergence risk) is large, the likelihood of moving from the convergence regime to the no-convergence regime is expected to be relatively high. Similarly, we expect the slope coefficient $\beta_{n c}$ for the level of the spread to be positive: if the interest rate spread is large, we expect the likelihood of staying in the no-convergence regime to be high.

For our second conditional variable, $\left(\Delta I R S_{t}\right)^{+}$, we expect different signs for the slope coefficients. That is, given that an increase in the interest rate spread is typically 
followed by a decrease (as shown in section 4), and given that we already incorporate the level of the spread, we expect that the slope on the change in the spread is positive for the convergence probability $\left(\gamma_{1, c}>0\right)$ and negative for the no-convergence probability $\left(\gamma_{1, n c}<0\right)$. For the sake of completeness, we also include $\left(\Delta I R S_{t}\right)^{-}$as explanatory variable for the regime probabilities.

The model introduced above describes the behavior of currency rates under the true or actual probability measure. To price options, we need the currency process under the risk-neutral probability measure. This paper is, to our best knowledge, the first to distinguish risk-neutral and actual regime switching probabilities. Bollen, Gray, and Whaley (2000) also use option prices to estimate regime-switching models, but they assume that the risk of regime switches is diversifiable, so that actual and risk-neutral probabilities coincide. In our case, regime switches are associated with Euro convergence risk, and it is likely that this important risk is priced. As outlined below, the use of both currency and option data allows us to analyze whether there is a difference between riskneutral and actual regime switching probabilities.

Moving from the actual to the risk-neutral probability measure changes two aspects of our model. First of all, in a risk-neutral world the drift of the currency rate should equal the difference between the domestic and foreign short maturity interest rates. Second, the regime-switching probabilities under the risk-neutral probability measure may differ from the actual probabilities. We model the risk-neutral switching probabilities $Q_{t}$ in the following way

$$
Q_{t}=\left[\begin{array}{cc}
q_{c, c}\left(x_{t}\right) & 1-q_{c, c}\left(x_{t}\right) \\
1-q_{n c, n c}\left(x_{t}\right) & q_{n c, n c}\left(x_{t}\right)
\end{array}\right]
$$

with

$$
q_{c, c}\left(x_{t}\right)=\Phi\left(\alpha_{c}+\widetilde{\beta}_{c} I R S_{t}+\gamma_{1, c}\left(\Delta I R S_{t}\right)^{+}+\gamma_{2, c}\left(\Delta I R S_{t}\right)^{-}\right)
$$

and 


$$
q_{n c, n c}\left(x_{t}\right)=\Phi\left(\alpha_{n c}+\widetilde{\beta}_{n c} I R S_{t}+\gamma_{1, n c}\left(\Delta I R S_{t}\right)^{+}+\gamma_{2, n c}\left(\Delta I R S_{t}\right)^{-}\right)
$$

We thus allow the slope coefficient on the IRS level to change when moving from the actual to the risk-neutral measure. To interpret this change, note that a positive convergence risk premium is obtained if the risk-neutral probability of staying in the convergence regime is smaller than the actual probability, and if the risk-neutral probability of staying in the no-convergence regime is larger than the actual probability. Combined with the expected signs for the actual slope parameters, a positive risk premium corresponds to the following expected inequalities for the risk-neutral and actual slope parameters

$$
\widetilde{\beta}_{c}<\beta_{c}<0, \widetilde{\beta}_{n c}>\beta_{n c}>0
$$

Our specification thus implies that high convergence risk, as represented by a high interest rate spread, corresponds to a higher risk premium on convergence risk. If the interest rate spread is zero, actual and risk-neutral probabilities coincide in our specification, reflecting the absence of convergence risk. In order to maintain a parsimonious model, we do not allow for risk premia on the lagged changes in the interest rate spread.

Our model implies that there are two components to the wedge between the implied volatility and realized volatility. The first component is a risk premium component. Intuitively, since investors do not observe the current regime of a country and given the difference between risk-neutral and actual probabilities, investors use conservative probabilities to price options, so that the option implied volatility (which reflects the risk-neutral expected volatility over the life of the option) exceeds the actual expected realized volatility. This component of the wedge will be positively related to the interest rate spread. Secondly, the model generates a difference between the actual expected volatility and realized volatility: in each week the actual regime is realized, which can either be the high- or low-volatility regime. If the realized regime is most often 
the low-volatility convergence regime (which one would expect ex-post for countries that actually converged), this second term would be positive most of the time, although temporary increases in convergence risk (i.e., temporary switches to the high-volatility regime) imply a negative sign for this term. This is line with Figures 3-6, where we indeed see a positive wedge on average, but also short periods with a negative wedge, which would coincide with a period of rapid deterioration in credibility.

\subsection{Model estimation}

For each country, the estimation methodology consists of two steps. In the first step, we estimate the regime-switching model under the actual probability measure using data on the currency rate. For this part, we use Maximum Likelihood for parameter estimation, as developed by Hamilton $(1989,1994)$ and Gray (1996). As a byproduct, this estimation methodology yields at each point in time the investor's assessment of the likelihood of being in a given regime, conditional upon the past observations on the currency rates. Bayesian updating is used to calculate these conditional regime probabilities. ${ }^{12}$

The second part of the estimation methodology focuses on the risk-neutral parameters of the model, i.e. the slope parameters in the switching probabilities in equations (12) and (13). We introduce a new estimation methodology for this. The methodology is based on the pricing formula for options in regime-switching models developed by Campbell and $\operatorname{Li}(2002) .{ }^{13}$ Denote $\pi_{t}^{Q}$ the risk-neutral probability that the current regime is the convergence regime, conditional upon the investor's information set at time $t$. The formula of Campbell and $\mathrm{Li}$ shows that the option price is a weighted average of two Black-Scholes (BS) type formulas. The first term is the product of the risk-neutral convergence regime probability $\pi_{t}^{Q}$ and a BS formula. The volatility parameter in this BS formula is given by the risk-neutral expectation of the average volatility over the life of the option, given that the current regime is the convergence

\footnotetext{
${ }^{12}$ We use the term regime probability to denote the probability that the regime is in a given state, conditional upon the information set at that time. This should not be confused with the switching probabilities in equation (11).

${ }^{13}$ The formula of Campbell and $\mathrm{Li}$ (2002) can be seen as a discrete-time case of the Hull and White (1987) formula.
} 
regime. The second term is similar, and expresses the contribution from the possibility of being in the no-convergence regime. It is important to note that the conditional regime probabilities are given under the risk-neutral measure. Also, the expectation of the average volatility over the option life involves the risk-neutral switching probabilities. We then set up the following iterative estimation strategy.

In step 1 we invert the option pricing formula to determine at each date the riskneutral convergence regime probability $\pi_{t}^{Q}$ from the observed 2-month option price. To calculate the expected average volatility in the pricing expression of Campbell and $\mathrm{Li}$, we use the parameters under the actual probability measure, as estimated using ML. For the second step we derive the following equation for the option-implied regime probability

$$
\pi_{t+1}^{Q}=E_{t}\left(\pi_{t+1}^{Q}\right)+\varepsilon_{t+1}=\pi_{t}^{Q} q_{c, c}\left(x_{t}\right)+\left(1-\pi_{t}^{Q}\right)\left(1-q_{n c, n c}\left(x_{t}\right)\right)+\varepsilon_{t+1}
$$

Given the time series for the risk-neutral regime probability obtained in the first step, we can estimate the risk-neutral slope parameters in the switching probabilities $q_{c, c}\left(x_{t}\right)$ and $q_{n c, n c}\left(x_{t}\right)$ by applying nonlinear least squares to equation (18). ${ }^{14}$

Finally, we iterate these two steps, where we now use in step 1 the risk-neutral expected volatility over the option life using the risk-neutral parameters obtained from the previous iteration. We stop when convergence is obtained.

In short, our estimation procedure filters out a time series for the risk-neutral regime probability from observed option prices, and then estimates the risk-neutral switching parameters using this time series.

\subsection{Estimation results}

Table 6 presents the estimation results for the regime-switching model. We start by discussing the results for the actual process of currency rates. First of all, for all countries

\footnotetext{
${ }^{14}$ Recall that the constant terms $\alpha_{\mathrm{c}}$ and $\alpha_{\mathrm{nc}}$ and the slope parameters on the changes in the interest rate spread $\left(\gamma_{1, c}, \gamma_{2, c}, \gamma_{1, n c}, \gamma_{2, n c}\right)$ are assumed to be the same under the actual and risk-neutral measure, so that these parameters are not re-estimated.
} 
we clearly find evidence for the existence of a high-volatility regime and a low-volatility regime, which we interpret as the no-convergence and convergence regime respectively. For example, for Italy the annualized volatility is $0.68 \%$ in the convergence regime and $9.47 \%$ in the no-convergence regime. As discussed earlier, we interpret the low volatility in the convergence regime as trading generated volatility, which will thus disappear once currencies are fixed. In addition to the volatility differences, we find for all countries (except Belgium) that the drift of the currency rate is lowest (and negative) in the noconvergence regime. Thus, in the no-convergence regime, currencies typically depreciate relative to the Deutschemark. The results also clearly show that the volatility parameters can be estimated much more precisely than the drift parameters.

The parameter estimates for the regime probabilities reflect the time-varying nature of convergence risk. The estimates show that higher interest rate spreads imply that it is less likely to stay in the convergence regime, while the likelihood of staying in the no-convergence regime increases with the interest rate spread. For example, if the interest rate spread is at its average level, the probability of staying in the convergence regime varies from $33.0 \%$ for Italy to $93.3 \%$ for Belgium. If the interest rate spread is equal to zero, this probability ranges from $90.1 \%$ for Spain to $96.4 \%$ for Belgium. A similar impact of the interest rate spread is obtained for the no-convergence switching probabilities. This clearly shows that there are important changes in convergence risk over time. In addition to the level effect of the interest rate spread, the lagged change in the spread also affects the regime probabilities to some extent. Inspired by the results in section 4, we allow for an asymmetric impact of the lagged spread change. The results are in general in line with the findings in section 4, although in some cases the parameters are not significantly different from zero. An increase in the interest rate spread increases (decreases) the probability of staying in the convergence (no-convergence) regime, correcting for the current level for the interest spread. A lagged decrease in the interest spread does not significantly influence the regime probabilities.

Next, we turn to the risk-neutral switching probabilities. As explained above, we allow the risk-neutral slope coefficient on the level of the IRS to be different from the actual slope coefficient. The results in table 6 show that for all countries the inequalities in equation (17) hold, implying a positive risk premium on convergence risk. Thus, 
relative to the actual switching probabilities, the risk-neutral probabilities imply a higher likelihood of (i) moving to the no-convergence regime and (ii) staying in this regime. For example, at the average level of the IRS, the risk-neutral probabilities of staying in the convergence regime range from $0.3 \%$ for Italy to $89.5 \%$ for Belgium. These numbers are clearly lower than the actual regime probabilities mentioned above.

Finally, we calculate convergence probabilities for all four countries. The convergence probability is defined as the probability that the regime at Jan 1, 1999, is the convergence regime. These probabilities are calculated at each date, using the regime probabilities at that date and the probability matrix of regime switches. We calculate both the actual convergence probabilities, obtained from the currency data, and the risk-neutral probabilities. Figures 9-12 graph the time series of these convergence probabilities. The graphs reflect the differences in convergence risk across countries. For Belgium, convergence probabilities are high and relatively constant over time, and the difference between actual and risk-neutral probabilities is relatively small. For France, there is more variation in the convergence probability. Lund (1999) finds that on the basis of interest rate spreads it is very hard to detect variation in convergence probabilities for Belgium and France.

For Italy and Spain, the picture is quite different. For these countries, there is considerable time variation in the convergence probabilities, and the large difference between the actual and risk-neutral probabilities reflects the importance of the convergence risk premium over the 1992-1998 period. In line with the declining trend in the wedge for the converging countries, Figures 9-12 also show that the difference between actual and risk-neutral convergence probabilities is decreasing. Figures 11 and 12 for Italy and Spain can be compared to figure 11 of Lund (1999), which shows the EMU probability estimated from interest rate data for Spain and Italy. Most strikingly, the comparison shows that on the basis of currency option data, convergence probabilities get close to one (around 90\%) at the end of 1997 and in 1998, while on the basis of interest rate data the convergence probabilities are between $50 \%$ and $80 \%$ at the end of 1997 and 1998. Even in August 1998, when it was essentially clear which countries would participate, interest rate based convergence probabilities were much lower than the option-based probabilities. 


\section{Conclusion}

In this paper we empirically analyzed confidence building on the likelihood of Euro convergence, using a new dataset on currency option prices. Motivated by a theoretical model of confidence building, we find empirical evidence for a gradual resolution of uncertainty over policy commitment, even after correcting for observed improvements in economic circumstances (exogenous learning). In addition, we find that confidence building on policy commitment speeds up after periods of high uncertainty.

In the second part of the paper, we propose a regime-switching option pricing model that captures the confidence building process. We estimate the model using both currency rate and option data. The parameter estimates of this model confirm the timevarying and asymmetric nature of convergence risk. Importantly, we also find that currency option prices contain a significant risk premium for convergence risk. This model could be useful to assess the convergence likelihood for countries that may join the Euro in the future.

There are several interesting topics for further research. For example, the regimeswitching model for the currency rate could be extended to a model for the joint behavior of the interest rate spread and the currency rate. In addition, it may be worthwhile to study the joint convergence behavior of the countries involved. Related to this, it may also be useful to incorporate the time variation in cross-country correlations of interest rates, currency rates, and currency volatility when analyzing the Euro convergence process. Finally, the concept of confidence building may be relevant in other applications, such as the impact of timing of unfavorable corporate news on the evolution of equity and corporate bond prices. 


\section{Bibliography}

Ait-Sahalia, Y. and A. Lo, 1998, "Nonparametric estimation of state-price densities implicit in financial asset prices," Journal of Finance, 53, 499-547.

Adao, B., and L. Barros, 2000, "Interest rate spreads implicit in options: Spain and Italy against Germany," Applied Financial Economics, 10, 155-161.

Ang, A., and G. Bekaert, 2001, "Regime Switches in Interest Rates", Working Paper, Columbia University.

Bates, D., 1999, "Financial Markets' Assessments of EMU," Carnegie-Rochester Conference Series on Public Policy, 51:1, 229-269.

Barro, R., 1986, "Reputation in a Model of Monetary Policy with Incomplete Information", Journal of Monetary Economics, 17, 3-20.

Barro, R., and D.B. Gordon, 1983, "Rules, Discretion and Reputation in a Model of Monetary Policy,” Journal of Monetary Economics, 12, 101-121.

Bollen, N.P.B., S.F. Gray, and R.E. Whaley, 2000, "Regime Switching in Foreign Exchange Rates: Evidence from Currency Option Prices", Journal of Econometrics, 94, 239-276.

Bottazzi, J. and A. Hueffmann, 2000, "FX Derivatives with Pre-Announced Peg: EMU Ins”, Working Paper Credit Suisse First Boston.

Campbell, S.D., and C. Li, 2002, “Option Pricing in Regime-Switching Environments”, Working Paper, University of Pennsylvania. 
Campa, Jose and Kevin Chang, 1998a, "ERM Realignment Risk and its Economic Determinants as Reflected in Cross-Rate Options," Economic Journal, 108, 1046-1066.

Campa, Jose, Kevin Chang and Robert Reider, 1998b, "Implied Exchange Rate Distributions: Evidence from OTC Option Markets", Journal of International Money and Finance, 17, No. 1, 117-160.

Campa, Jose, Kevin Chang, 1996, "Arbitrage-Based Tests of Exchange Rates Target Zones: Evidence from ERM Cross-Rate Options," American Economic Review, 86, No. $4,726-740$.

Canina, L. and S. Figlewski, 1993, "The Informational Content of Implied Volatility", Review of Financial Studies 6, 659-682.

Cherian, J. and E. Perotti, 2001, 'Option Pricing and Foreign Investment under Political Risk", Journal of International Economics, 55, 359-377.

Dahlquist, M., and S. Gray, 2000, "Regime-switching and Interest Rates in the European Monetary System", Journal of International Economics, 50, 399-419.

David, A., and P. Veronesi, 2002, "Option Prices with Uncertain Fundamentals: Theory and Evidence on the Dynamics of Implied Volatilities," Working Paper, University of Chicago.

Dumas, B., Jennergren, and Naslund, 1995a, " Realignment Risk and Currency Option Pricing within a Target Zone", European Economic Review, 39, 1523-1544.

Dumas, B., Jennergren, and Naslund, 1995b, "Siegel's paradox and the pricing of currency options," Journal of International Money and Finance, 14, 213-223. 
Erb, C., C. Harvey, and T. Viskanta, 1996, "Political Risk, Financial Risk and Economic Risk," Financial Analysts Journal, 52:6, 28-46.

Favero, C., F. Giavazzi, F. Iacone, and G. Tabellini, 2000, "Extracting Information from Asset Prices: the Methodology of EMU Calculators", European Economic Review, 44, $1607-1632$.

Gray, S.F., 1996, "Modeling the Conditional Distribution of Interest Rates as a RegimeSwitching Process", Journal of Financial Economics, 42, 27-62.

Hamilton, J.D., 1989, "A New Approach to the Economic Analysis of Nonstationary Time Series and the Business Cycle", Econometrica, 57, 357-284.

Hamilton, J.D., 1994, Time Series Analysis, Princeton University Press, New Jersey.

Hull, J., and A. White, 1987, "The Pricing of Options on Assets with Stochastic Volatilities" Journal of Finance, 42, 281-300.

Jackwerth, J. and M. Rubinstein, 1996, "Recovering probability distributions from contemporary security prices," Journal of Finance, 51, 1611-1631.

Lund, J., 1999, "A Model for Studying the Effect of EMU on European Yield Curves", European Finance Review, 2, 321-363.

Maltz, A., 1996, "Using option prices to estimate realignment probabilities in the European monetary system", Journal of International Money and Finance, 15, 717-748.

Perotti, E.C., and L. Laeven, 2001, "Confidence Building in Emerging Markets", Working Paper, University of Amsterdam. 
Perotti, E.C., and P. van Oijen, 2001, "Privatization, Market Development and Political Risk in Emerging Economies", Journal of International Money and Finance, 20 (1), p. 43-69.

Rogoff, K., 1986, "Reputational Constraints on Monetary Policy," in K. Brunner and A. Meltzer (eds.), Carnegie-Rochester Conference Series on Public Policy, 26, 141-181. 
Table 1. Summary Statistics on Volatility Wedge. The table provides summary statistics on the volatility wedge, which is defined as the implied volatility on a 2-month currency option minus the realized volatility over the remaining maturity (estimated using daily log-currency changes). The wedge is measured in Black volatility points. All statistics are calculated over the full sample period.

\begin{tabular}{ccccc}
\hline & Average Wedge & $\begin{array}{c}\text { First Quartile } \\
\text { Wedge }\end{array}$ & Median Wedge & $\begin{array}{c}\text { Third Quartile } \\
\text { Wedge }\end{array}$ \\
\hline Belgium & 0.46 & 0.18 & 0.38 & 0.64 \\
France & 0.44 & -0.08 & 0.51 & 1.16 \\
Italy & 0.68 & -0.04 & 1.03 & 2.68 \\
Spain & 1.69 & 0.42 & 1.82 & 3.56 \\
\hline Sweden & 0.19 & -0.56 & 0.21 & 1.70 \\
UK & 0.25 & -0.54 & 0.29 & 1.72
\end{tabular}

Table 2. Summary Statistics on Implied Volatility and Interest Rate Spreads. The table gives summary statistics on implied volatilities of 2-month currency options, and on the interest rate spread (a country's swap rate minus the German swap rate). All swaps have 10 years to maturity. All statistics are calculated over the full sample period.

\begin{tabular}{ccccc}
\hline & Average IV & Median IV & $\begin{array}{c}\text { Average Interest } \\
\text { Rate Spread }\end{array}$ & $\begin{array}{c}\text { Median Interest } \\
\text { Rate Spread }\end{array}$ \\
\hline Belgium & 0.85 & 0.65 & $0.21 \%$ & $0.08 \%$ \\
France & 2.75 & 2.45 & $0.24 \%$ & $0.05 \%$ \\
Italy & 7.28 & 7.10 & $2.71 \%$ & $2.79 \%$ \\
Spain & 5.52 & 5.60 & $2.60 \%$ & $2.89 \%$ \\
\hline Sweden & 8.41 & 8.40 & $1.99 \%$ & $1.87 \%$ \\
UK & 7.39 & 7.50 & $1.37 \%$ & $1.37 \%$
\end{tabular}


Table 3. Two-Step Regression: Volatility Wedge, Implied Volatility and Interest Rate Spread Regressions. Fixed effects panel data models are estimated using the 'within' least-squares estimator. The dependent variable is respectively the volatility wedge, implied volatility, and the interest rate spread, for the four converging countries (Belgium, France, Italy, and Spain) and over the full sample period. Explanatory variables are the inflation rate, budget deficit and ICRG risk measure of each country, and a linear time-trend. In the first step, the dependent variable is regressed on the budget deficit and inflation rate. In a second step, the first-step residuals are regressed on the time trend and the political risk measure. The table reports the slope coefficient estimates and associated t-ratios; the constant terms are not reported. All measures are measured in percentages, and the observation frequency is monthly.

\begin{tabular}{cccccl}
\hline \multirow{2}{*}{ Wedge } & $\begin{array}{l}\text { Inflation } \\
\text { (t-ratio })\end{array}$ & $\begin{array}{l}\text { Budget Deficit } \\
\text { (t-ratio) }\end{array}$ & $\begin{array}{l}\text { ICRG Political } \\
\text { Risk (t-ratio) }\end{array}$ & $\begin{array}{l}\text { Time Trend } \\
\text { (t-ratio) }\end{array}$ & $\begin{array}{l}\text { First and } \\
\text { second-step } \\
\text { 'Within' }{ }^{2}\end{array}$ \\
& 1.397 & 0.179 & -0.0671 & -0.020 & $11.4 \%$ vs $9.4 \%$ \\
IV & $(3.78)$ & $(2.13)$ & $(1.68)$ & $(1.75)$ & \\
& 1.023 & 0.152 & -0.151 & -0.021 & $42.3 \%$ vs $19.3 \%$ \\
IRS & $(3.41)$ & $(1.99)$ & $(-2.81)$ & $(-2.41)$ & \\
& 1.237 & 0.437 & -0.114 & -0.014 & $49.4 \%$ vs $21.5 \%$ \\
& $(3.81)$ & $(1.70)$ & $(-2.51)$ & $(-1.85)$ & \\
\hline
\end{tabular}

Table 4. Asymmetric Time Series Model for Changes in IV and Interest Rate Spread. Weekly changes in the implied volatility and interest rate spread are regressed on lagged changes, allowing for an asymmetric effect of positive and negative changes. The table reports the slope coefficient estimates and associated t-ratios; the constant terms are not reported.

\begin{tabular}{lllll}
\hline & Belgium & France & \multicolumn{1}{c}{ Italy } & \multicolumn{1}{c}{ Spain } \\
\hline \multicolumn{4}{c}{ Panel A: Implied Volatility Regression } \\
\hline Coefficient $(\Delta I V)^{+}$ & -0.17 & -0.14 & -0.25 & -0.12 \\
& $(-2.13)$ & $(-1.59)$ & $(-3.73)$ & $(-1.73)$ \\
Coefficient $(\Delta I V)^{-}$ & 0.21 & -0.10 & -0.14 & 0.04 \\
& $(1.82)$ & $(-1.37)$ & $(-1.57)$ & $(0.61)$ \\
\hline Coefficient $(\Delta I R S)^{+}$ & -0.25 & -0.15 & -0.13 & -0.03 \\
& $(-2.70)$ & $(-1.94)$ & $(-1.55)$ & $(-0.95)$ \\
Coefficient $(\Delta I R S)^{-}$ & -0.09 & -0.05 & 0.02 & 0.06 \\
& $(-0.95)$ & $(-0.58)$ & $(0.31)$ & $(0.81)$
\end{tabular}


Table 5. Change in Volatility Wedge in Volatile Markets. The table presents the average cumulative change in the volatility wedge, conditional upon $2.5 \% / 97.5 \%$ percentile shocks in the interest rate spread. The cumulative change includes the contemporaneous movement in the wedge at the week of the interest rate spread shock. The wedge change is calculated in deviation from the average change, and measured in volatility points.

Large downward interest rate spread Large upward interest rate spread shock

shock

\begin{tabular}{lllllll}
\hline & $\begin{array}{l}1 \text { week } \\
\text { wedge } \\
\text { change }\end{array}$ & $\begin{array}{l}2 \text { week } \\
\text { wedge } \\
\text { change }\end{array}$ & $\begin{array}{l}4 \text { week } \\
\text { wedge } \\
\text { change }\end{array}$ & $\begin{array}{l}\text { 1 week } \\
\text { wedge } \\
\text { change }\end{array}$ & $\begin{array}{l}2 \text { week } \\
\text { wedge } \\
\text { change }\end{array}$ & $\begin{array}{l}4 \text { week } \\
\text { wedge } \\
\text { change }\end{array}$ \\
\hline Belgium & -0.13 & -0.12 & -0.22 & 0.27 & 0.14 & 0.02 \\
France & -0.20 & -0.26 & -0.23 & 0.30 & 0.41 & 0.32 \\
Italy & -0.29 & -0.33 & -0.29 & 1.08 & 1.03 & 0.83 \\
Spain & -0.16 & -0.24 & -0.31 & 0.34 & 0.15 & -0.07
\end{tabular}


Table 6. Parameter Estimates Regime-Switching Model. Panel A of the table gives estimates of the regime-switching model for weekly currency rates (section 5). Estimation is performed in two steps. First, the parameters under the actual probability measure are estimated using ML. Second, the iterative procedure discussed in section 5 is used to estimate the risk-neutral parameters. Panel B gives the regimeswitching probabilities at a zero interest rate spread and the average interest rate spread. The means and volatilities in the currency return process are annualized. A ' *' denotes significantly different at the $10 \%$ level, '**' denotes significance on the $5 \%$ level, and ' $* * *$ ' on the $1 \%$ level. For the risk-neutral parameters, standard errors are calculated from the final, second-step nonlinear regression.

$$
\begin{array}{llll}
\text { Belgium } & \text { France } & \text { Italy } & \text { Spain }
\end{array}
$$

Panel A: Parameters Regime-Switching Model

\begin{tabular}{|c|c|c|c|c|}
\hline$\sigma_{\mathrm{c}}$ & $* 0.21 \%$ & $* 0.98 \%$ & $* 0.68 \%$ & $* * 1.80 \%$ \\
\hline$\sigma_{\mathrm{nc}}$ & $* * * 1.04 \%$ & $* * * 4.31 \%$ & $* * * 9.47 \%$ & $* * * 10.85 \%$ \\
\hline$\mu_{\mathrm{c}}$ & $-0.08 \%$ & $* 0.30 \%$ & $-0.81 \%$ & $0.16 \%$ \\
\hline$\mu_{\mathrm{nc}}$ & $0.06 \%$ & $-0.21 \%$ & $*-5.06 \%$ & $* *-15.59 \%$ \\
\hline$\beta_{\mathrm{c}}$ & $* *-1.58$ & $* *-0.71$ & $*_{*}-0.79$ & $* *_{-} 0.39$ \\
\hline$\beta_{\mathrm{nc}}$ & $* * 1.25$ & $* * 0.36$ & $* 0.34$ & 0.03 \\
\hline$\gamma_{1, \mathrm{c}}$ & -0.04 & $* * 0.31$ & 0.09 & $* 0.17$ \\
\hline$\gamma_{2, \mathrm{c}}$ & 0.00 & 0.05 & -0.02 & 0.11 \\
\hline$\gamma_{1, \mathrm{nc}}$ & 0.00 & $* *-1.33$ & $*_{-0} 0.19$ & $*_{-} 0.86$ \\
\hline$\gamma_{2, \mathrm{nc}}$ & -0.01 & -0.12 & 0.10 & $* 0.32$ \\
\hline$\beta_{c}$ & $* *-1.78$ & $* *-2.21$ & $* *-1.65$ & $*_{-} 0.70$ \\
\hline$\widetilde{\beta}_{n c}$ & $* 1.54$ & $* 0.82$ & $* 0.75$ & 0.07 \\
\hline \multicolumn{5}{|c|}{ Panel B: Regime-Switching Probabilities } \\
\hline$p_{c, c}\left(x_{t}=0\right)$ & $96.41 \%$ & $95.05 \%$ & $95.54 \%$ & $90.15 \%$ \\
\hline$p_{c, c}\left(x_{t}=\bar{x}\right)$ & $93.29 \%$ & $93.05 \%$ & $32.96 \%$ & $60.87 \%$ \\
\hline$q_{c, c}\left(x_{t}=\bar{x}\right)$ & $89.47 \%$ & $86.86 \%$ & $0.28 \%$ & $29.81 \%$ \\
\hline$p_{n c, n c}\left(x_{t}=0\right)$ & $94.29 \%$ & $91.15 \%$ & $96.41 \%$ & $72.57 \%$ \\
\hline$p_{n c, n c}\left(x_{t}=\bar{x}\right)$ & $96.64 \%$ & $92.46 \%$ & $99.67 \%$ & $75.11 \%$ \\
\hline$q_{n c, n c}\left(x_{t}=\bar{x}\right)$ & $98.06 \%$ & $93.90 \%$ & $99.99 \%$ & $78.29 \%$ \\
\hline
\end{tabular}




\section{Figures}

Figure 1. Theoretical Confidence Building Model: Political Cost and Interest Rate Benefits Over Time.

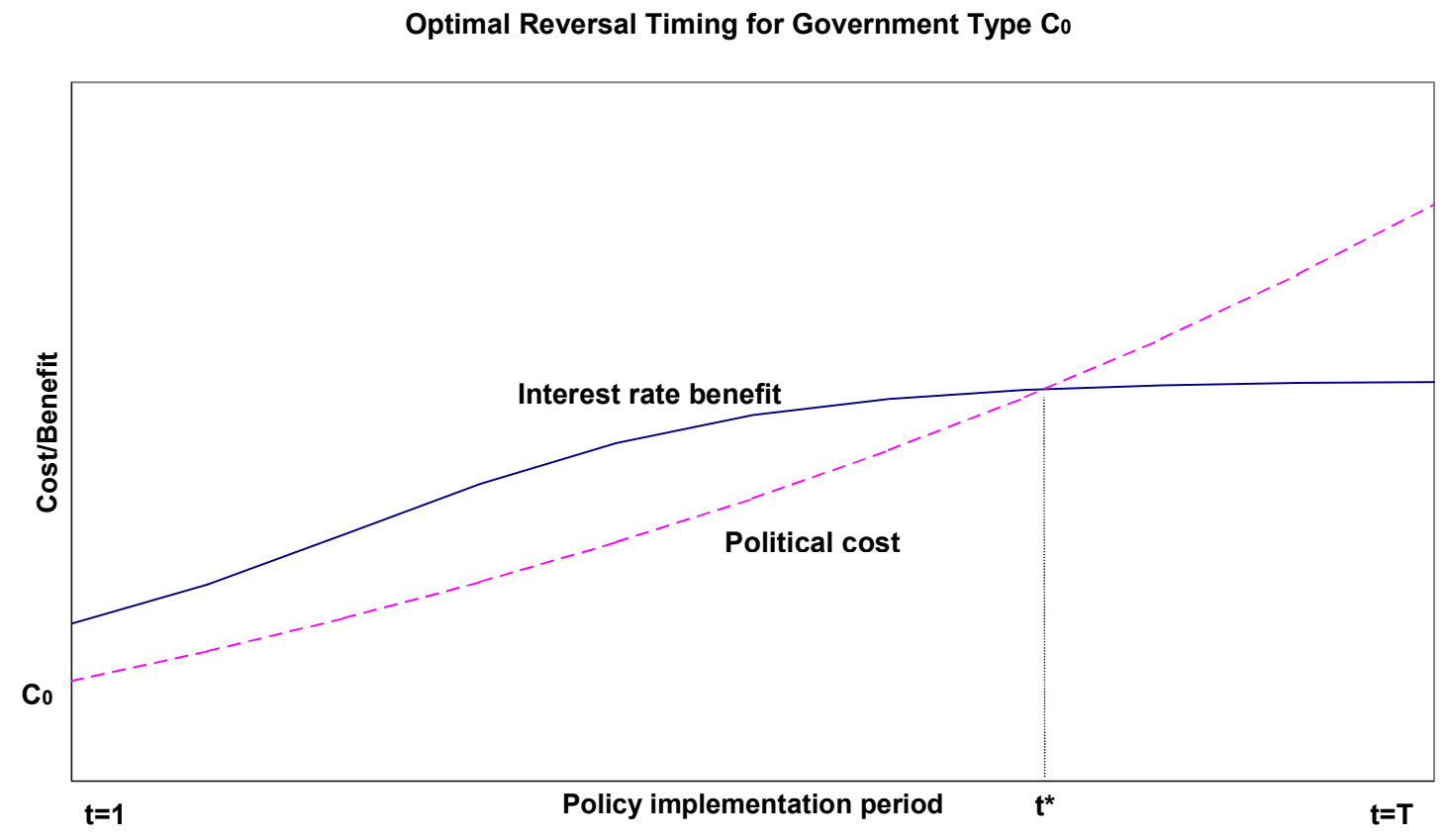


Figures 2a-b. Confidence Building according to Theoretical Model: With and without Intermediate Shocks. Figure 2a shows the hazard rate per period of a policy reversal, for the case without intermediate shocks to the political cost, and the case of an adverse shock of 1.5 at $t=5$. Figure $2 b$ shows again the case without intermediate shocks, and the case of a decrease in the political cost of 1.5 at $t=5$. All results are based on the theoretical model in section 2, assuming a uniform distribution of types, $r=3 \%, R=11 \%$, $\mathrm{D}=50$ or 75 , and an average political cost $\mathrm{C}_{\mathrm{o}}=10$ rising marginally (at a rate of $0.1 \%$ ) over time until $\mathrm{T}$.
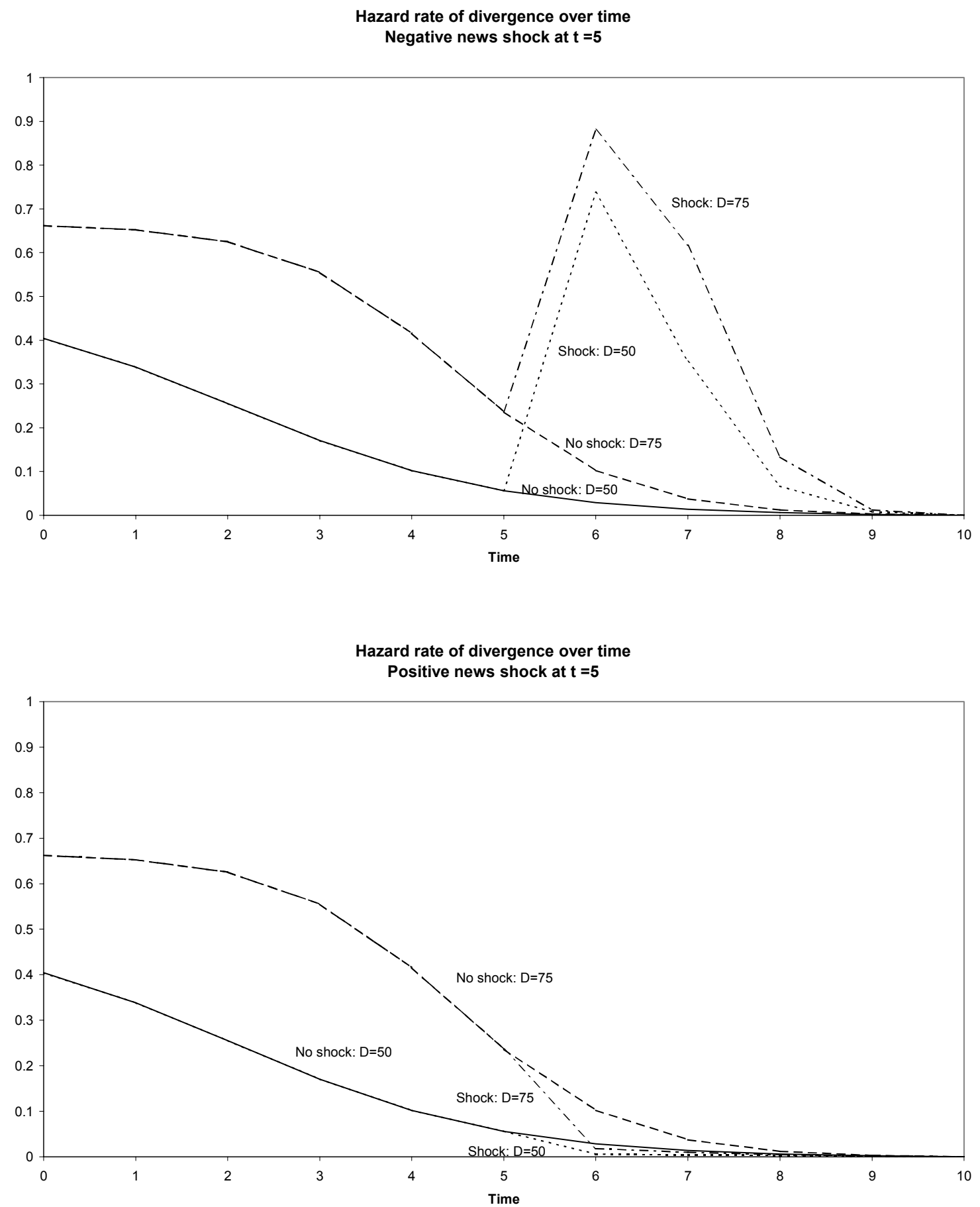
Figures 3-8. Daily time series of volatility wedge and implied volatility of 2-month options. The volatility wedge is defined as the implied volatility on a 2 -month currency option minus the realized volatility over the remaining maturity (estimated using daily currency changes). The wedge and the implied volatility are measured in Black volatility points.
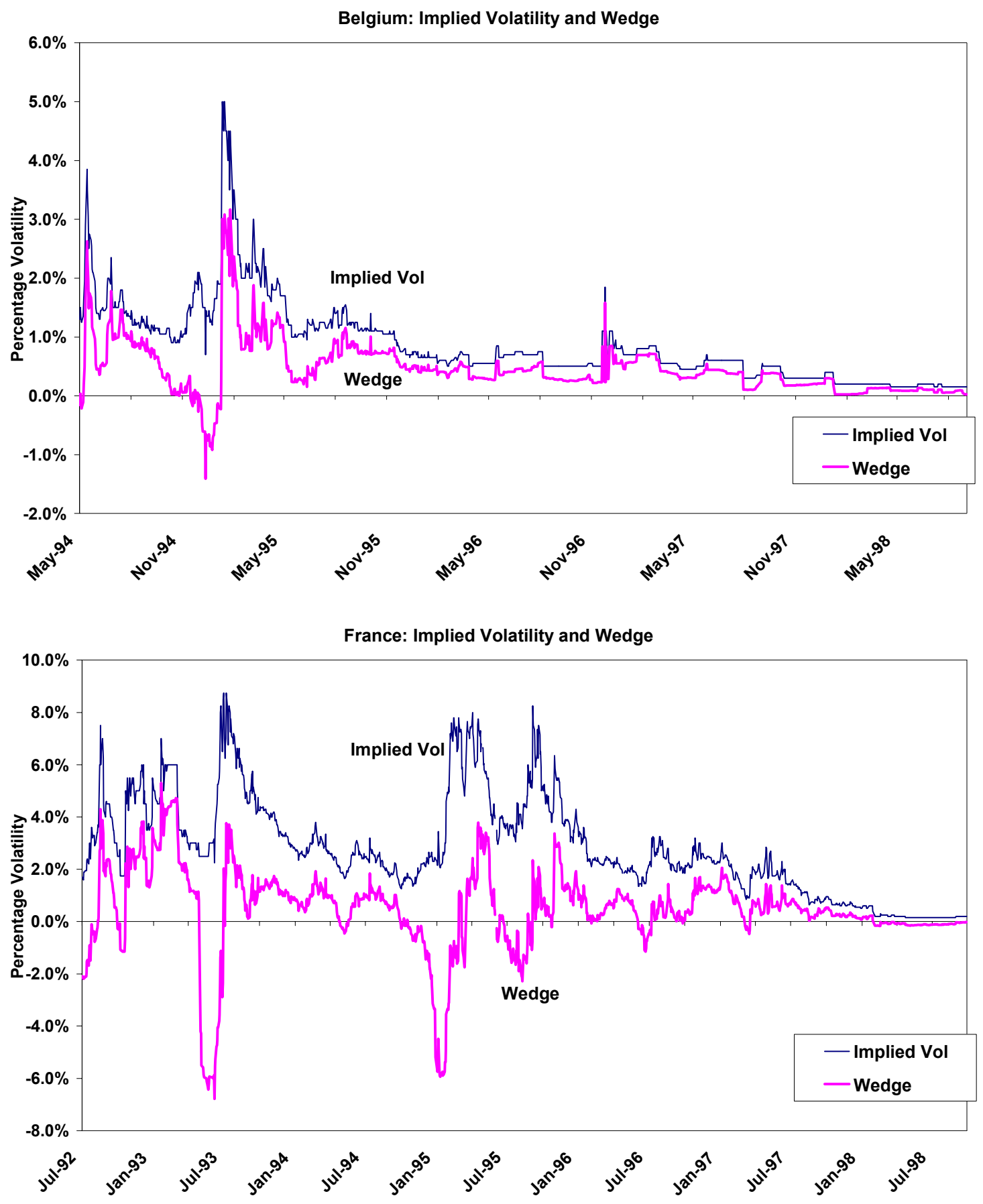

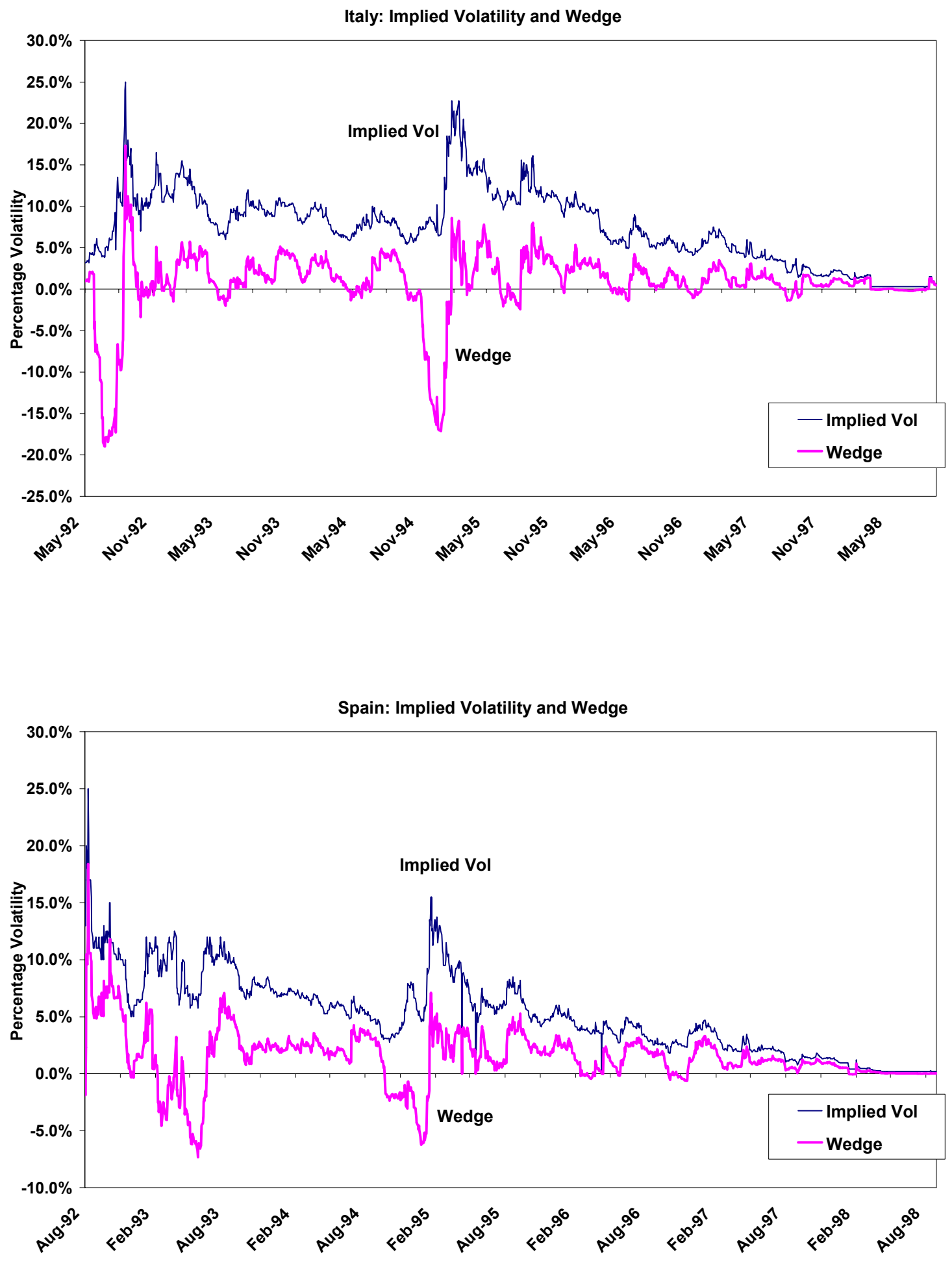

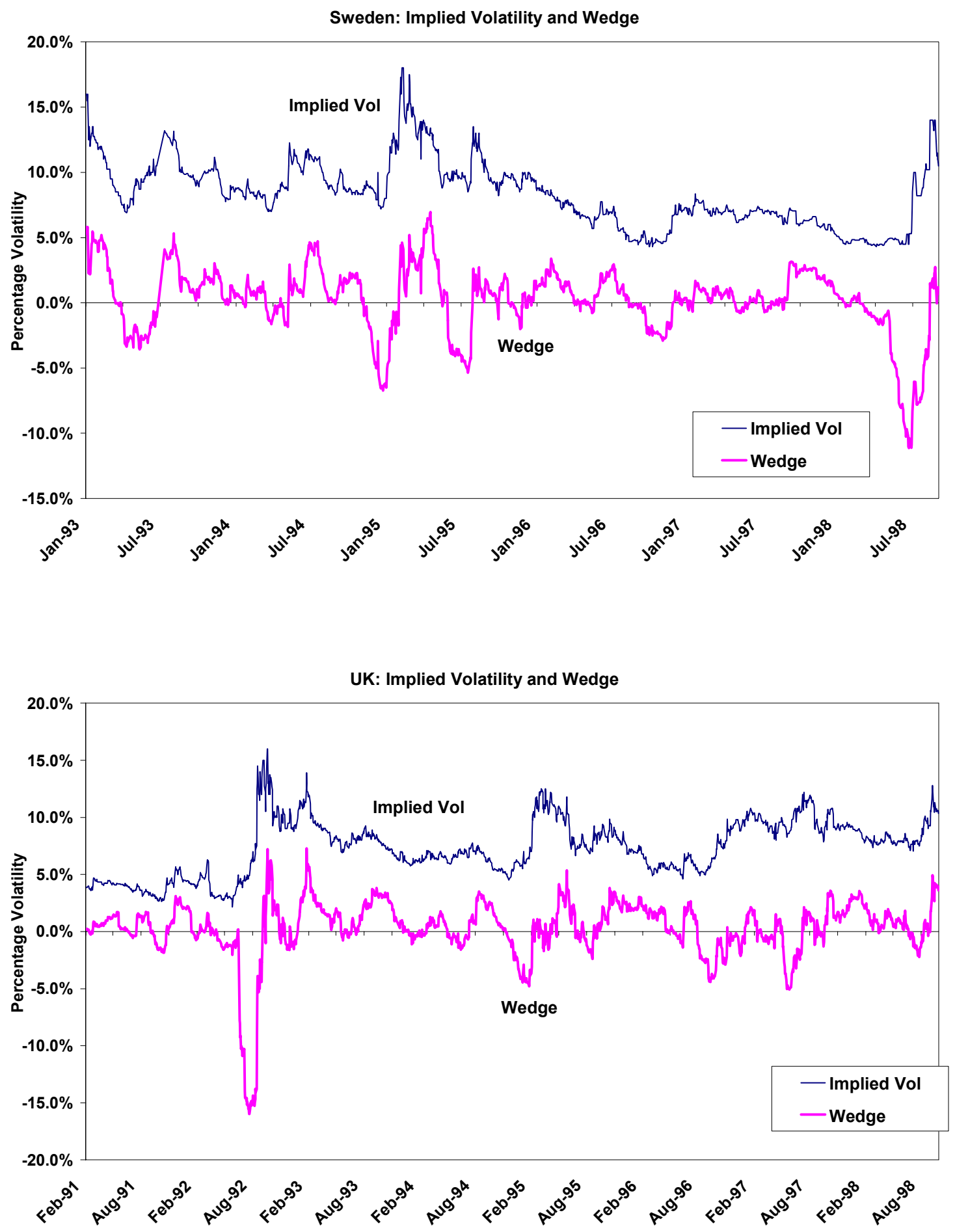
Figures 9-12. Weekly time series of convergence probabilities implied by regime-switching model. The figures depict the actual and risk-neutral probabilities of Euro convergence for Belgium, France, Italy, and Spain. The probabilities are derived from the regime-switching model of section 5. The convergence probability is defined as the probability that the regime at Jan 1, 1999 is the converging regime.

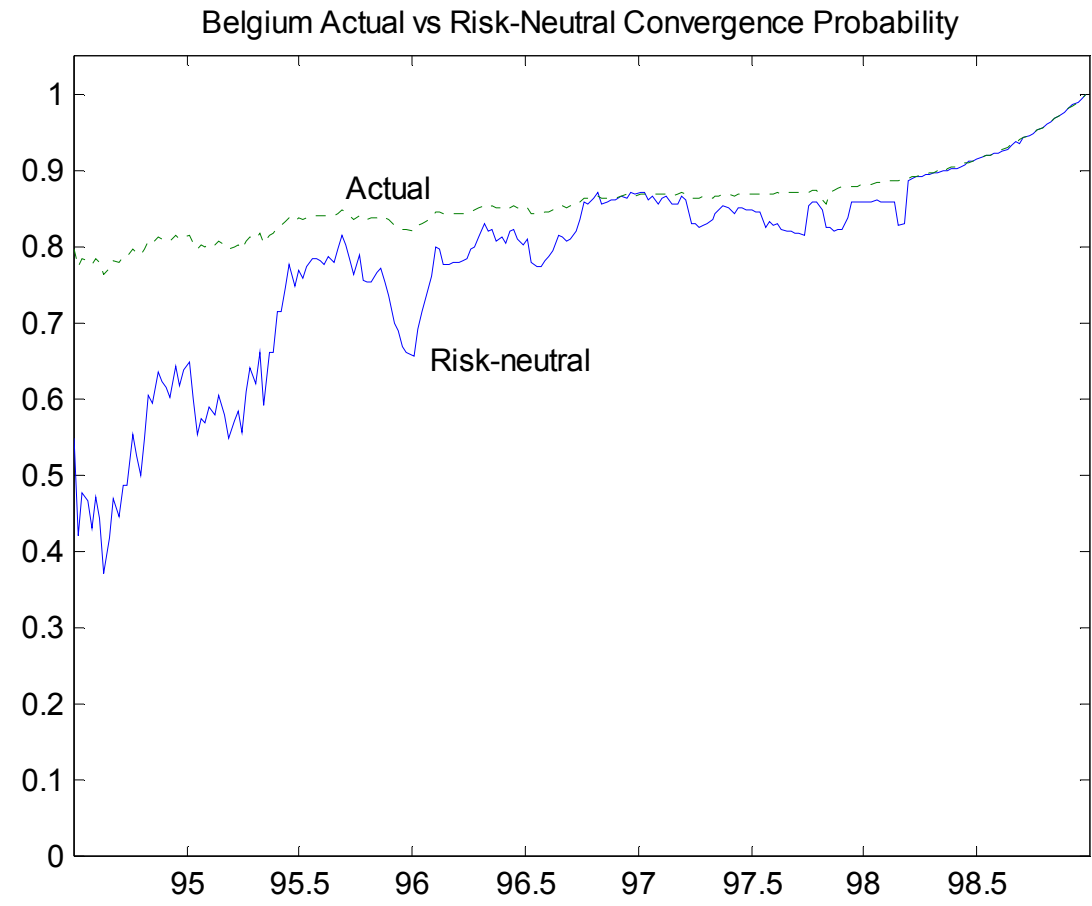

France Actual vs Risk-Neutral Convergence Probability

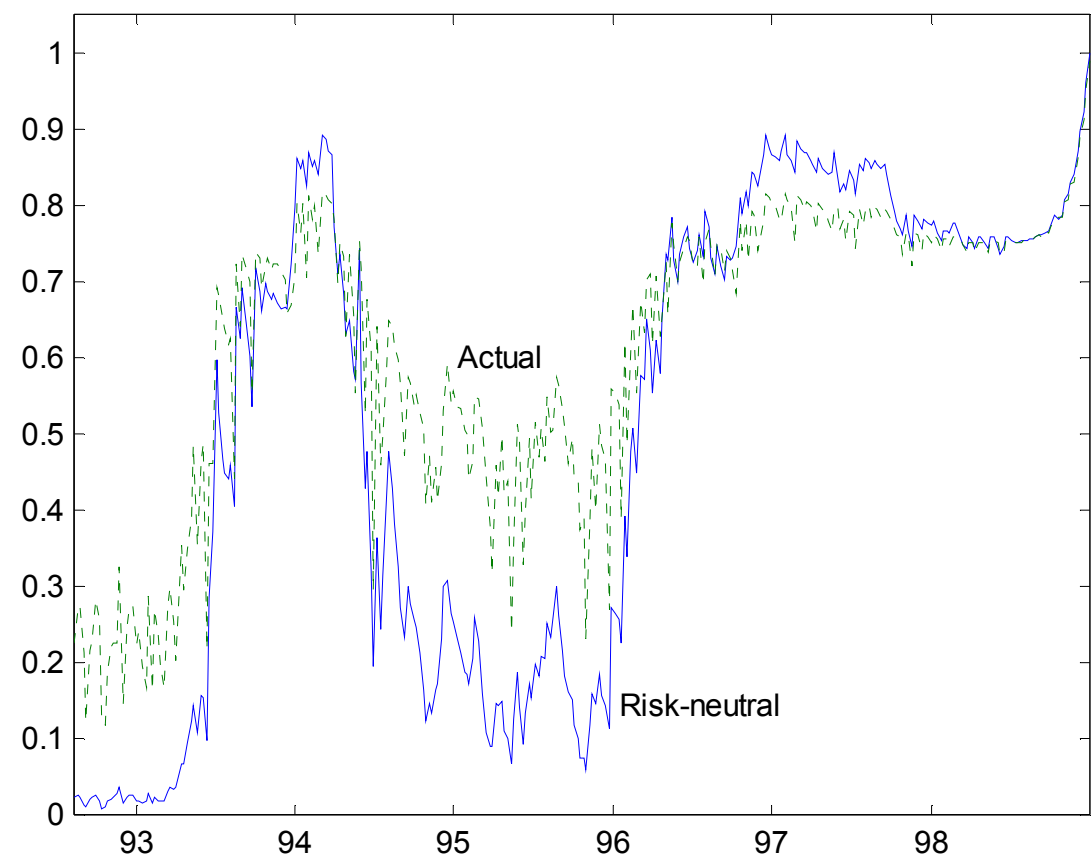


Italy Actual vs Risk-Neutral Convergence Probability
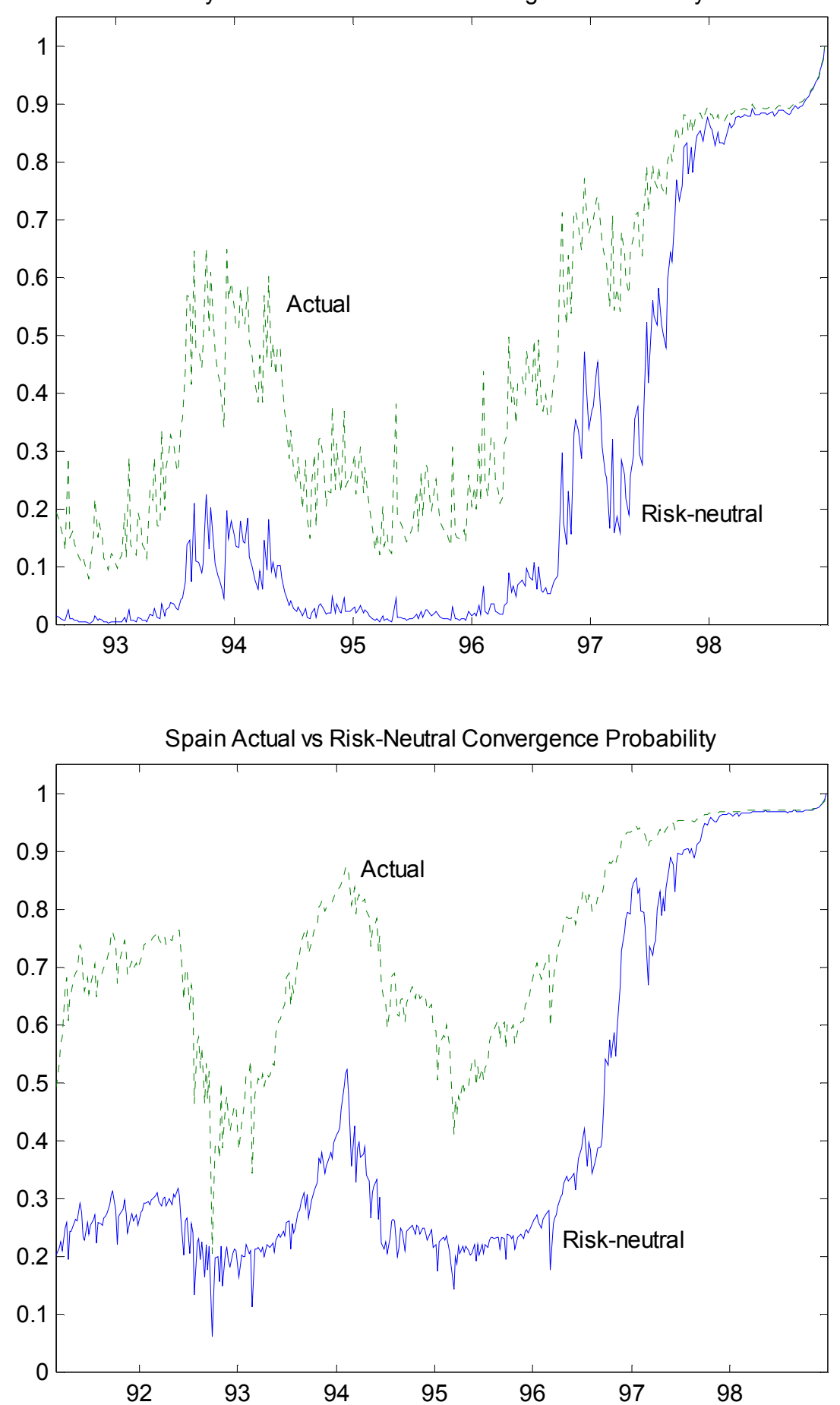